\title{
COVID Lock Down and Household Ear Trauma......!
}

\section{Chintale SG*}

\author{
Department of ENT, JIIU'S IIMS \& R Medical College, India
}

*Corresponding author: Sambhaji Govind Chintale, Associate Professor, Department of ENT, JIIU'S IIMS \& R Medical College, Maharashtra, India, Tel: +919970323030; Email: drsamchinto@gmail.com

\section{Editorial}

As we know that COVID pandemic has started in December 2019 in china and it widely spread to the all over the world in short span of time in many western countries and Asian country too in 2 to 3 month due to which all country has to stop all activity and many country has made decision to lock down the country for 1 month, 2 month and 3 month depending on situation of corona virus in their state.

In our developing country we have to face lot of problem like COVID situation, lock down economic crisis, daily wages problems, and because of many financial problems for poor people who earn and run their family on daily basis had suffered lots. This leads to family in house quarrels in between family members. In India like country where male dominancy in society home assault increases in lock down period due to frustration and depression in lockdown period because no outdoor activity in this lockdown period. In my observation as ENT practitioner and field researcher observed lots of cases of ear trauma during this period of 3 month duration which are usually very less in numbers as per my observation before lock down usually 1 to 2 cases per month of ear trauma in household come to for consultation. In last 3 month this cases has increased from 1 to 2 cases per month to 7 to 8 cases per month by observation. This type of ear trauma may causes hearing loss and trouble in the family member so we need to focus on care of our own family member in this COVID lock down period, so that these types of cases will lower down in coming days. With proper handling of economic burden of family in lockdown with great positive attitude and healthy way many such type of incidence we may prevent in coming days and preventing the ear damage and hearing loss problem. With counselling of patients and their relatives in such crisis we can make awareness regarding such problems in society. Its need of hours to deal this pandemic in harmonious way without blaming and torturing to the household member.

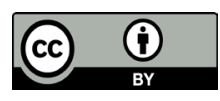

